\title{
Why the IPCC should evolve in response to the UNFCCC bottom-up strategy adopted in Paris? An opinion from the French Association for Disaster Risk Reduction
}

\author{
Maud H. Devès ${ }^{1,4,}{ }^{*}$, Michel Lang ${ }^{2,4}$, Paul-Henri Bourrelier ${ }^{4}$, François Valérian ${ }^{3,4}$ \\ ${ }^{1}$ Institut de Physique du Globe de Paris, CNRS UMR 7154 \& Centre de Recherche Psychanalyse \\ Médecine et Société, CNRS EA 3522 - Université Paris Diderot, Sorbonne Paris Cité \\ ${ }^{2}$ IRSTEA, Centre de Lyon-Villeurbanne, Unité de recherche Hydrologie-Hydraulique \\ ${ }^{3}$ Conseil Général de l'Economie, CNAM, LabEx ReFi \\ ${ }^{4}$ Association Française de Prévention des Catastrophes Naturelles (AFPCN), Scientific Committee \\ *Corresponding author: deves@ipgp.fr
}

\section{Abstract}

The levels of greenhouse gases in the atmosphere keep increasing every year, and despite the adoption of the Paris agreement, one cannot expect any significant dip in the trend in the near future. We may therefore legitimately question the efficiency of the current governance system, notably concerning the interplay between science and policy. The strategy adopted by the UNFCCC in Paris contrasts with the strategy adopted in Kyoto, as it endorses a dynamic that is more bottom-up. Its success will depend greatly on the ability of the actors to mobilize on climate issues and to find ways to work together. Scientific expertise has a key role to play to this respect. This paper is a reflection led by the French Association for Disaster Risk Reduction on how the Intergovernmental Panel on Climate Change could evolve in order to usefully accompany that strategy. Introducing more reflexivity in the assessment process and widening aspects of the expertise to a more diverse and transdisciplinary range of actors could improve the treatment of uncertainties, multi-scale interactions and the appropriation of expertise, as well as the integration of adaptation and mitigation policies. In practical terms, this could involve more working groups, which could become more focused, drawing up shorter but more frequent reports, and taking account of the "grey" expert literature. The implementation of such an approach merits further investigation, because these improvements could help address the governance challenges in climate change.

Key words: climate change, climate governance, expertise, IPCC, science and policy

\section{Introduction}

After five assessment reports and almost thirty years of negotiations, the alert message raised by climate scientists was eventually heard. In December 2015, in Paris, the decision was taken to hold "the increase in the global average temperature to well below $2^{\circ} \mathrm{C}$ above pre-industrial levels" and to pursue "efforts to limit the temperature increase to $1.5^{\circ} \mathrm{C}$ above pre-industrial levels, recognizing that this would significantly reduce the risks and impacts of climate change". Countries agreed to make significant efforts to reach that ambitious common goal, but each country remains responsible 
Author-produced version of the article published in Environmental Science \& Policy (2017), vol. 78, p. 142-148

The original publication is available at http://www.sciencedirect.com/science/article/pii/S1462901117310109

for the design of its own strategy as no new international regulation system was defined ${ }^{1}$. Thus the question that is now raised is how to organize this bottom-up strategy efficiently.

To that respect, the scientific expertise will have to play an important role. So far, the Intergovernmental Panel on Climate Change (IPCC) and its counterpart, the Subsidiary Body for Scientific and Technological Advice (SBSTA), have been the main instruments of the international expertise at the crossroad between research and policy on climate. The role of the IPCC has been particularly important in raising awareness on the risks associated with human-activities. For this purpose, the experts developed a unique assessment process. If the latter has been as much praised as criticized over time (e.g. Schrope, 2001 and Tol, 2011 for snapshots of the controversies at two different times), there is no doubt that it represents the most comprehensive compilation of knowledge on climate change to date. However, the context of the expertise evolving, one can wonder if the Panel will have to evolve too, in order to accompany the overall dynamics.

This is the topic of the present paper. Section 2 presents a review of the current assessment process and its evolution since the setting up of the Panel. In section 3, we give our analysis of the challenges that are posed. Section 4 contains a series of recommendations for changes. Our reflection is the result of an iterative thinking process undertaken in the framework of the scientific council of the French Association for Disaster Risk Reduction. At the occasion of the release of the fifth IPCC report, a group of experts specialised on climate issues re-examined the organisation of IPCC expertise and brainstormed on how it could evolve in the future. Interviews were undertaken with the IPCC focal point in France and with leading French climate scientists, some of who had been involved in IPCC. The methodology we adopted then has been iterative and integrative. We wrote a preliminary report we sent off to the public authorities and disseminated to a wider public at the occasion of a study day (held on July 2014). The public was composed of a lay public and of experts coming from different academic disciplines and from various private and public sectors. Three subsequent seminars were organised to address the controversial issues or the points of misunderstanding that emerged in the discussion. The current paper results from this integrative thinking process. The work has been completed by a review of peer-reviewed academic research but also of the "grey" literature. Indeed, we believe that articles written by actors from outside the academic world are crucial to help understand how the interplay of science and policy could operate better.

\section{The current organization of the IPCC expertise}

Created in 1988 under the patronage of the United Nation Environment Program (UNEP) and the World Meteorological Organization (WMO), the IPCC was entrusted with the task of assessing the influence of anthropogenic greenhouse gas (GHG) emissions on climate change, as well as its potential effect on societies, and formulating "realistic response strategies for the management of the climate change issue" (IPCC, 1990). Since then, the Panel has submitted five assessment reports (AR) that confirm the effect of anthropic GHG emissions on climate change and predict a high level of

\footnotetext{
${ }^{1}$ The Paris Agreement has now entered into force as more than 55 Parties to the Convention (accounting in total for at least an estimated $55 \%$ of the total global greenhouse gas emissions) have deposited their instruments of ratification, acceptance, approval or accession with the Depositary.
} 
Author-produced version of the article published in Environmental Science \& Policy (2017), vol. 78, p. 142-148

The original publication is available at http://www.sciencedirect.com/science/article/pii/S1462901117310109

associated risks. As pointed out by Jones (2013), the assessment of this effect has changed from not quantified in 1990 (AR1) to discernible in 1995 (AR2), rising to a probability of 2/3 in 2001 (AR3), 9/10 in 2007 (AR4) and finally 9.5/10 in 2013 (AR5). The last report also predicts dangerous impacts on societies and, more generally, on biodiversity if the rate of emissions does not decrease significantly (or even cease) by the middle of the $21^{\text {st }}$ century.

The mandate of the Panel has always been to be policy-relevant but not policy-prescriptive. This is a real challenge as going from academic knowledge to decision-making requires awareness of policy processes. Climate experts and government representatives therefore have to work together at some point of the assessment. The biases introduced by these interactions have already been abundantly commented in the literature and this is not the point we want to make here (e.g. Hecht and Tirpak (1995), Franz (1997), Agrawala (1998a, b), Skodvin (2000), Bodansky (2001), Demeritt (2001), Bolin (2007), Zillman (2009), Hulme and Mahony (2010), Hulme et al. (2010), Pielke (2010), Schiermeier (2010a and b), Beck (2011), Beck (2013), Dahan (2013), Schiermeier (2014); Stocker and Plattner (2014), Beck et al. (2014), Dahan and Guillemot (2015) or more recently Aykut and Dayan (2015)).

The IPCC has an intergovernmental status; all decisions are voted at unanimity during plenary sessions of the general assembly. The latter is composed of representatives of all parties and of observer organizations such as non-governmental organizations (NGO) but associations of civil society and lobbies cannot vote. From the first report, the tasks have been divided between three main Working Groups (WG), a special task group dedicated to greenhouse gas inventories and a group dedicated to data management. WGI has always been in charge of evaluating available scientific information on the physical and chemical mechanisms of climate change; WGII of assessing the effects of climate change on societies and the environment and WGIII of formulating response strategies. The only significant change took place between the first and the second assessment reports when a distinction was made between adaptation and mitigation strategies. WGII has been then concerned with impacts, adaptation and vulnerability while WGIII has focussed on mitigation (Table 1).

Table 1: Evolution of the mandates of the WGs through the five assessment cycles.

\begin{tabular}{|l|l|l|l|}
\hline Assessment report & Working Group 1 & Working Group 2 & Working Group 3 \\
\hline AR1 $-1990 \& 1992$ & $\begin{array}{l}\text { Scientific assessment } \\
\text { of Climate Change }\end{array}$ & $\begin{array}{l}\text { Assessment of impacts of Climate } \\
\text { Change }\end{array}$ & $\begin{array}{l}\text { The IPCC Response } \\
\text { Strategies }\end{array}$ \\
\hline AR2 - 1995 & $\begin{array}{l}\text { The science of } \\
\text { Climate Change }\end{array}$ & $\begin{array}{l}\text { Impacts, Adaptation, and Mitigation of } \\
\text { Climate Change: Scientific-technic } \\
\text { analyses }\end{array}$ & $\begin{array}{l}\text { Economic and Social } \\
\text { Dimensions of } \\
\text { Climate Change }\end{array}$ \\
\hline AR3 - 2001 & The scientific basis & Impacts, Adaptation, and Vulnerability & Mitigation \\
\hline $\begin{array}{l}\text { AR4 }-2007 \\
\text { AR5 }-2013 \& 2014\end{array}$ & $\begin{array}{l}\text { The physical science } \\
\text { basis }\end{array}$ & Impacts, Adaptation, and Vulnerability & $\begin{array}{l}\text { Mitigation of Climate } \\
\text { Change }\end{array}$ \\
\hline
\end{tabular}

A small Bureau oversees the work of the different groups. Its members are elected in order to represent the different working groups and to reflect reasonably well the diversity of the parties. The members of the Bureau(s) are the experts with the most impact on the assessment. Observer organizations and the civil society can attend during the voting steps of the assessment process but do not directly contribute to the development of the reports. The bureau designs the skeleton of the reports and nominates the Coordinating Lead Authors (CLA) and the Lead Authors (LA) of each 
Author-produced version of the article published in Environmental Science \& Policy (2017), vol. 78, p. 142-148

The original publication is available at http://www.sciencedirect.com/science/article/pii/S1462901117310109

chapter. CLAs have a key role in coordinating the development of large parts of the reports. In carrying out this task, the CLAs rely on many contributing authors who, despite their greater number, do not really have a significant control on the final output. But there are not just experts who write; some review. Review Editors (RE) are particularly important because they are the ones who decide what should be changed or not in response to comments and criticisms. The review process occurs in three stages. A first-order draft is first sent to the scientific reviewers. The second and the third draft versions are sent both to scientists and to governments. This is particularly important for the drafting of the SPMs (Summaries for Policy Makers), which is really under the responsibility of the Bureau.

The assessments themselves are based on a review of the existing literature. The choice was made to focus solely on peer-reviewed academic papers and minimize references to the so-called "grey" literature. Three main types of documents are produced during an assessment: Reports, Technical Summaries and Summaries for Policy Makers (SPM). They do not correspond to the same level of synthesis, are not intended for the same readership and are not involved in the same adoption procedure. The scientific reports are notoriously long (typically thousands of pages) and difficult to digest but they include a hundred-page Technical Summary and a Frequently Asked Questions supplement that are easier to manage. The SPMs are much shorter (half the length) and more directly aimed at decision-making. SPMs play a very specific role in the process. Whereas reports and technical summaries are discussed, voted and accepted as a whole, SPMs are voted line by line during plenary sessions. Since the acceptance is subject to unanimity and not majority voting, a government can hold the whole process to ransom if it does not like a particular formulation.

Models and scenarios have always been central to the IPCC expertise but their use and articulation has evolved through time. It is actually one of the main changes in the assessment process. Before AR5, future emission pathways were estimated from educated guesses on socio-economical choices and were input into climate simulations to assess possible effects of resulting climate change on societies. In the case of AR5, four climate forcing scenarios (called Representative Concentration Pathways - RCPs) were chosen from the peer-reviewed literature as plausible pathways to reach four distinct levels of radiative forcing by 2100 . As each RCP provides only one of many possibilities, four pathways were chosen to cover a broad range of possible futures. This change in procedure has allowed the adoption of a parallel working process reducing "the time lags between the creation of emissions scenarios, their use in climate modelling, and the application of the resulting climate scenarios in research on impacts, adaptation and vulnerability" (Moss et al., 2010). While climate modellers prepare simulations using the RCPs, integrated assessment modellers can now develop a set of new socioeconomic and emissions scenarios to answer the question: "what are the ways in which the world could develop in order to reach a particular radiative forcing pathway?".

\section{The limits of the current assessment process in the context of an evolution of the expertise needs}

Based on a review of more than 10000 climate papers in the peer-reviewed scientific literature from 1991-2011, Cook et al. (2013) showed that the number of papers rejecting the consensus on anthropogenic warming is a vanishingly small proportion of the published research (also see Oreskes, 2004). But this relative scientific consensus is far from being shared by public opinion (see Howe et al., 2015, for an analysis of geographic variations in the USA; Cody et al., 2015, for an analysis of the "climate change sentiment" on Twitter). This discrepancy does not encourage political action and the 
Author-produced version of the article published in Environmental Science \& Policy (2017), vol. 78, p. 142-148

The original publication is available at http://www.sciencedirect.com/science/article/pii/S1462901117310109

success of the bottom-up strategy endorsed by the UNFCCC in Paris depends on the ability of a diversity of actors to get mobilise on climate issues at different scales and in various sectors (e.g. Aubertin et al., 2015). It also depends on the ability of experts' bodies to accompany them on their fields.

\subsection{The evolution of the context of the expertise}

The context of the expertise has evolved through time but the structure of the Panel has remained very much the same since the creation of the Panel. Its mandate was originally focussed on proving the effect of anthropic GHG emissions on climate change and on proposing mitigation options (this appears clearly in the evolution of the names of the WGs, Table 1). Although corresponding to an important modification in the mandate of the experts, the issue of adaptation has emerged more discretely in the debate (Beck, 2011; Burton and DPUN, 2005). The protocol of the expertise was only modified at the margins, the review of adaptation strategies being included within the tasks of WGII in AR2. Since adaptation has been pushed into the negotiations by developing countries, this issue has progressively taken up centre stage. Adaptation used to be seen as the marginal cost of failed mitigation (Pielke, 2005). It now appears as an inevitable complement to mitigation strategies and, if WGI has historically played the principal role, WGII and WGIII have become more and more key.

Today, understanding the mechanisms and effects of climate remain crucial but the challenge stands more in articulating predictions derived at the global scale to smaller scales strategies (taking into consideration the multiplicity of the actors who operate at different scales and are subjected to different constraints), and in combining, in a practical manner, strategies of mitigation with strategies of adaptation. Passing from global climate simulations and average trends to local models of risks and advice on response strategies requires the ability to link up a wide range of different temporal and spatial scales and take into account the existence of a great diversity of actors. However, this is easier said than done. Downscaling from global climatic simulations to models of impacts is notoriously difficult, and introduces additional sources of uncertainty. Moreover, the challenges introduced by linking together different scales are not merely technical. According to Edenhofer and Minx (2014), who use the metaphor of mapmakers and navigators, an assessment report "provides a living map, drawn in a social learning process between scientists (mapmakers) and policy-makers (navigators), to be used to traverse the largely unknown territory of climate policy". Creating useful maps requires making them at the temporal and spatial scales at which actors actually navigate. Taking French coastal risk management as an example, Devès (2014) shows that such an exercise is not trivial. The average sea-level rise trend provided by IPCC is useful to illustrate the reality of the risks at the global scale but is much less well adapted to the decisionmaking process at smaller scales. Stakeholders on the French Atlantic coast report that, because the uncertainties of the models are greater than the risks they are already exposed to, they cannot really understand why they should adapt their risk management plans. Sea-level rise can indeed vary significantly from one region to another (e.g. depending on the role played by isostatic rebound, tectonic movements, etc.). Local actors are asking for more precise models of impact so they can evaluate the risks and think about prevention. From their point of view, it would be difficult to implement concrete actions for climate as long as the agenda they might have to consider appears less constrained than the issues they have to manage on a day-to-day basis. 


\subsection{A need for more reflexivity}

If more interactions with all categories of actors could be expected from the Panel, many also ask for more reflexivity from the experts on the organisation of the interactions between science and policy. Beck (2011 \& 2014), Jasanoff et al. (1998) or Sarewitz (2011) argue that the governance scheme adopted by the UNFCCC have contributed to blur the message of the climate experts and opened avenues for criticism by the climate-sceptics. The actual scheme supposes a clear demarcation between science and policy. Experts are seen as simple facts-providers while policymakers are expected to negotiate depending on the system of values they believe in (Figure 1). Although this sequential model allows a clean share of responsibilities - protecting academic freedoms from the pressures of political expediency -, it does not reflect the reality of the interactions. In practice, knowledge cannot be hermetically separated from its political application and, in order to be politically relevant, the assessment process has to be adapted to the political context. Expert bodies have to be hybrid in some ways. In the case of IPCC, hybridity operates at different stages: the experts are selected from a list proposed by governments, the reports are reviewed by governmental experts, etc. But the necessity of taking into account political considerations also introduces biases. The need for country representativeness, for instance, puts a strain on the choice of experts, their scientific background not being the only criteria in the selection process. Less visible but also important are the arbitrages that are made at different steps in the process of translation of the scientific knowledge into operable knowledge. Even though the reports are built exclusively from academic literature, the experts have to make choices in selecting and organising the material they use and these have more or less direct political consequences. The fact that the governance scheme publicized by the UNFCCC does not make explicit these complexities nourish misunderstandings.
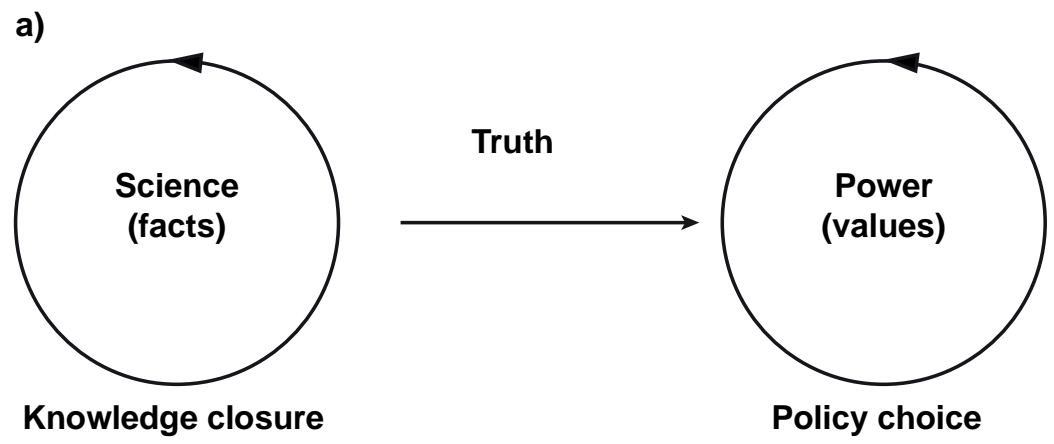

b)

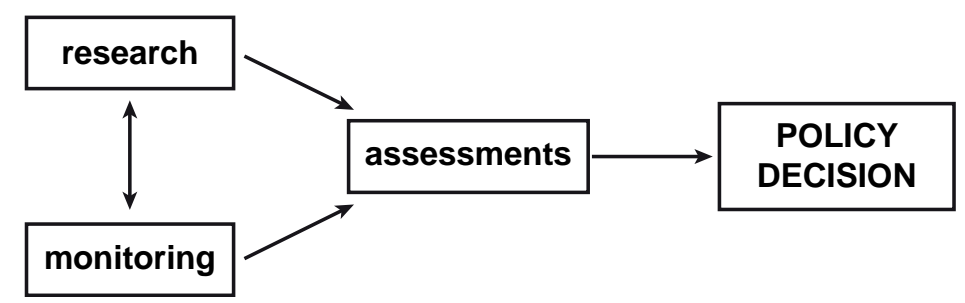

Figure 1 - A linear model of expertise in which science speaks "truth" to power. a) Theoretical model. b) United Nation climate governance scheme. Figure modified from Beck, 2011. 
Author-produced version of the article published in Environmental Science \& Policy (2017), vol. 78, p. 142-148

The original publication is available at http://www.sciencedirect.com/science/article/pii/S1462901117310109 doi : 10.1016/j.envsci.2017.10.001

\subsection{A need for a greater integration of the expertise across disciplines, sectors and countries}

The expertise could also evolve in the sense of a greater integration across disciplines, sectors and countries.

The longstanding international cooperation of physical research on climate has led to a progressive standardization of procedures but WGII and WGIII have to deal with more disparate observations and methods. Along time, WGI has become the leader of the expertise on climate change science. WGII and WGIII still have to share their field of expertise with institutions like the World Bank or the International Energy Agency. The diversity of the three WGs - in terms of mandate, composition and approach - reflects the multidisciplinary character of the expertise on climate but also demonstrates that an effort of integration is still required in order to develop the transdisciplinary approach that local and national practitioners would need to design and combine well-thought adaptation and mitigation strategies.

The choice to segment the Panel's tasks into three working groups dates from the creation of the Panel. It works well in the context of a sequential governance scheme, in which knowledge is seen as cumulative. Distinct disciplines or sectors address the issues of the causes and of the consequences, of hazard characterisation and of impact evaluation, of exposure and vulnerability and of response strategies. Such an approach is classic in risk assessment as it allows specialists to work in parallel but it has some limits. One can notably observe that the thematic separation of the three WGs broadly reproduces the traditional academic boundaries (Table 1). WGI covers the domain of the physical sciences (physics and chemistry of climate change), while WGIII is oriented towards the social sciences (socio-economics and policy) and WGII is slightly more hybrid (reflecting the topics it deals with, i.e. impact, risk and adaptation). This thematic separation tends to narrow the composition of the WGs to well-delimited research issues, with integration occurring essentially between closely related disciplines (see, for instance, the co-citation analysis of Bjurström and Polk, 2011 on AR3). This impedes the appropriation of the expertise results within the academic community itself. As an example, one can cite the study conducted by Vasileiadoua et al. (2011) on the citation rate of the four IPCC reports in the academic literature. Most citations come from the physical sciences (95\%) and only $5 \%$ from the social sciences, including $2 \%$ from economics and $2 \%$ from socio-political science. This result echoes the general under-representation of social sciences in the Panel (Victor, 2015); the few social scientists who are present belong to WGIII and focus on economics and $\mathrm{CO}_{2}$ emission scenarios (Hulme and Mahoney, 2010).

Some more efforts are also needed in terms of country representativeness. According to Vasileiadoua et al. (2011), IPCC reports are less frequently cited in developing countries than in developed countries (except for China, which is in $4^{\text {th }}$ position and India in $18^{\text {th }}$ of the top 20 countries quoting SPMs). Hulme and Mahony (2010) report an insufficient participation of scientists from non-industrialized countries. Gray et al. (2013) estimate that 129 countries have contributed to the IPCC over the past 25 years. Of these countries, a small proportion has dominated the drafting and editing of the IPCC reports. Roughly 21 countries account for $80 \%$ of all bodies participating in the reports. Five countries only (the USA, UK, Germany, Canada and Australia) account for over $50 \%$ of the participating bodies (not all of these countries have actually been very good at decreasing their GHG emissions), although many emerging economies, such as China, India and Brazil, are playing an increasing role within the IPCC. Although the participation tends to improve with every 
Author-produced version of the article published in Environmental Science \& Policy (2017), vol. 78, p. 142-148

The original publication is available at http://www.sciencedirect.com/science/article/pii/S1462901117310109

assessment, these observations highlight the difficulty of achieving a balance in the contributions from different parties in order to facilitate use of the expertise by all. This seems, however, particularly important as issues such as the distribution of responsibility between developed and developing countries are concerned.

\subsection{Going further than the consensus-based approach in the treatment of uncertainties}

An important limit to the expertise today is the way the Panel deals with the uncertainties. Consensus is a difficult objective to aim for and it is sometimes more accurate to explicit divergences.

The ultimate output of the IPCC reports are the SPM, which are voted line by line during plenary sessions. Such consensus is a major concern as it requires agreeing both on scientific facts and economic and social recommendations. From a pure scientific point of view, it is not easy as research always deals with unresolved questions and uncertainties. The condensation of a document from thousands to fifty pages requires making choices that, without being militant, cannot be strictly neutral. IPCC (2010) has developed a specific guidance note for a consistent treatment of uncertainties, based on two metrics, the first related to the confidence in the validity of a fact (degree of agreement), the second to the level of uncertainty (expressed by a probabilistic scale). The difficulty is that the three WGs have a very different level of practice of such metrics. These differences are not merely anecdotic but arise from different cultural and scientific backgrounds as well as from the complexity of the real under study, resulting in more or less quantitative approaches that can be focused on completely different scales in time and space or can be based on different types of observations and simulations. WGI refers to the output of physical models, which are compared and summarized with central and dispersion values. WGII declined to use a global model after the disputed study of Stern (2006). WGIII is using hundreds of models and thousands of scenarios that are far from being all related to real facts and behaviours. As stated by Jones (2011), the key point is to be able to summarize expert opinion for political decision. Socolow (2011) stresses that politics need to have clear output from the scientific community of what is possible to assert or not on the impact of climate change and related strategies. It is therefore important to clearly report on possible discrepancies between statements.

Science studies tend to focus on the interplay between experts and policy makers, but we should bear in mind that being a researcher is very different from being an expert and the linkage between them is also complex. First, it is rare for authorized representatives to formulate their demand in a strictly scientific way. Experts have to reformulate the question so they can answer it reasonably well given the knowledge and knowhow available at the time of assessment. This process requires segmenting a question that is "too big" into more specific issues. Every step of this reframing process requires the making of choices. By distinguishing three working groups, the Panel re-specified its mandate and, as discussed above, this has had a direct influence on the designation of the research disciplines to be taken into account in the assessment. This is true at even smaller scales. Chapters, sections, sub-sections, paragraphs, figures, etc., all correspond to specific choices that are more or less consensual because the way a question is addressed often depends on the knowledge and knowhow available to the researcher or expert. Secondly, even if the best choice could be made by research communities brought together around a discussion table, there are always parts of the real world that have not yet been studied. There are also many points on which consensus are difficult to reach, especially when dealing with new avenues of research where the state of knowledge is rapidly 
Author-produced version of the article published in Environmental Science \& Policy (2017), vol. 78, p. 142-148

The original publication is available at http://www.sciencedirect.com/science/article/pii/S1462901117310109

evolving. The formulation of a question may influence the way uncertainties are dealt with and the room left for the experts' subjective judgment. Moreover, even if a question is well posed, the answer can be associated with a level of uncertainty that is more or less easy to quantify. These uncertainties open the door to controversy. Tollefson (2013) reports the case of the exclusion of the West Antarctic Ice sheet from the review because of the uncertainties in the models used to predict the ice sheet's behaviour. According to Brysse et al. (2013) and O'Reilly et al. (2012), this decision resulted in a large underestimation of the sea-level rise.

Therefore, expert reports are clearly more focused on making choices for building wellinformed narratives to help in decision-making rather than synthetizing existing studies. The endusers of the expertise can expect all the building steps of these narratives to be explicit. So far, the Panel has provided a list of references and indications of uncertainty for most of their statements, thus grading the level of scientific consensus. However, they do not always set out the alternative options and the reasons they were not adopted. Since concatenating uncertainties with a limited set of indicators tends to blur the different issues and scales (e.g. Curry, 2011; Ebi, 2011), Oppenheimer et al. (2008) advise against drawing up a premature consensus that could lead to overlooking or underestimating critical uncertainties. Cooke (2015) proposes using methods of expert elicitation and cross-validation to improve the treatment of uncertainties. Hollin and Pearce (2015) insist on what they call the "certainty trap" and stress the importance for experts to acknowledge the discordance between scientific and public perceptions of uncertainty when communicating (e.g. in answering a journalist's question, it might appear inconsistent to use a short time scale to illustrate global warming; Ekwurzel et al., 2011; Hollin and Pearce, 2015). This is an important point of improvement because misunderstandings are still frequent, and not only with the lay public (e.g. debate on the interpretation of sea-level curves and uncertainties, Church et al. 2013; also see Maslin, 2013).

\section{Some recommendations for the evolution of the expertise}

After the "Climategate" controversy, and following a series of errors identified in 2010 on the fourth report (2007) of the IPCC (e.g. melting of Himalayan glaciers forecast for 2035 instead of 2350), the Inter Academy Council was mandated by the United Nations to conduct an audit on the functioning of the IPCC (Kintisch, 2010). The IAC did not cast doubt on the results of the assessments but called for a standardization of the guidelines between the three WGs, notably regarding the treatment of uncertainty. They also recommended 1) creating an Executive Committee with reduced rotating presidency, 2) improving the monitoring of the review process, notably by giving more importance to "review editors", 3) increased diversification of contributing disciplines, 4) developing a better communication strategy, 5) introducing a delay of 1 to 2 years between the release of the WGI report and the WGII and WGIII reports. Another audit was conducted for the Dutch parliament on the regional chapters of AR4 (2007) related to the Netherlands. The results of this analysis were released progressively on the Web, giving the public the possibility to discuss with scientists (via this approach, climate sceptics found an open forum of debate and scientists could respond publically) (Hajer, 2012). Very few errors were found eventually and there were no significant consequences on the results of the overall expertise. Hajer, 2012 (op. cit.) recommended 1) providing better explanations of the various steps of the reasoning on which the expertise is based, 2) carrying out regular exchanges with the public on the Web (and not only when the reports are published), 3) paying attention to respond rapidly to repeated criticisms, and to correct reported errors, 4) improving the communication of results and mobilizing intermediate bodies that can perform 
mediation between science and policy. Most of these recommendations, however, aimed at reinforcing the credibility of the expertise and resulted in a reinforcement of the academic character of the expertise. It was undoubtedly necessary at a time of great scepticism. One could wonder today, however, if the expertise should not evolve from purely academic to more use-oriented. In February 2015, IPCC experts discussed the organisation of their future work stressing the importance of making reports more user-friendly and fostering closer involvement of developing countries (IPCC, 2015). Although these are important points, the above discussion shows that deeper changes are required.

Instead of striving for a sequential model of interplay between science and policy, experts could concentrate on providing better explanations of why scientific and political considerations must be jointly taken into account to arrive at useful assessments. The difficulties that are inherent to any expertise should be made clear. Building a coherent narrative out of a fragmented and continuously evolving research landscape and formulating advice aimed at different sectors of the public - while finding a reasonable balance between accuracy and synthesis - is not trivial. It is crucial to track down the choices that are made at each stage of integration, especially in the case of IPCC whose expertise relies on complex systems. This requires a good level of reflexivity from the specialists who are involved in the expertise. It is not easy to rationalize what are the limitations of a tool/method/theory/speciality and to explore what may be the consequences on the overall expertise. This requires having a clear representation of the various levels of epistemic interactions. The tools developed by social scientists can help the experts to this respect in mapping out the areas of knowledge covered by each speciality and identifying possible gaps or redundancies (which are both causes of uncertainties and disagreements). Expert elicitation techniques, which are used by many expert bodies, can also be useful to force experts identifying potential controversies and provides quantitative indicators to discuss uncertainties. Explicit rationalization of the possible causes of disagreement is often more efficient than concatenating different types of uncertainties using simple pseudo-quantitative indicators as IPCC currently do.

On this topic of uncertainty, as on the content of expertise itself, the Panel would gain from involving more disciplines, notably from human and social sciences but not only. We believe however that the key to a true inter- or transdisciplinarity is to abandon (at least from time to time) parallel working and to allow specialists coming from different fields to interact with each other on a long time-frame (long enough to develop a common methodology and a common terminology). This can happen at the occasion of thematic reports (it happened for the SREX). Repeating such experiences frequently helps ensuring a certain level of continuity.

The IPCC assessment has expanded continuously over the last few decades - which is a sign of dynamism - but the reports has become very long. It is an efficient process for an immense body of knowledge to be shared among experts but many end-users are discouraged by the immensity of the reading task. Shorter and more focussed reports could allow a better presentation of the diversity of options and the associated uncertainties. It would also be easier to involve end-users in their preparation and/or review, which would facilitate the implementation of simple strategies, both scientifically well informed and politically efficient.

Administration experts, members of Parliaments, mayors, associations and NGOs, private companies, medias, etc., all contribute to the framing of the "climate change problem" and all form 
Author-produced version of the article published in Environmental Science \& Policy (2017), vol. 78, p. 142-148

The original publication is available at http://www.sciencedirect.com/science/article/pii/S1462901117310109

part of its solution. This is particularly true in terms of adaptation (e.g. Burton and DPUN, 2005; Dovers and Hezri, 2010). The choice to focus on academic literature was made to increase the scientific legitimacy of the reports but one could certainly try to find a better balance between legitimacy and credibility, authority and efficiency. As outlined by the InterAcademy Council (IAC, 2010), highly valuable information can be found in non-peer-reviewed sources, which could be relevant for WGI (large data sets), just as much as for WGII (organisations acting at the local level) or WGIII (industry-linked organisations). Technical reports, working papers, presentations and conference proceedings, as well as in fact sheets, bulletins, statistics, observational data sets and modelling results produced by government agencies, international organizations, universities, research centres, NGOs, corporations, professional associations and other groups contain appropriate information for inclusion in an assessment report. The exclusion of grey literature protects the expertise from lobbies - and this is a key point - but it also deprives the expertise from the knowledge and knowhow of its users. Depending on their sector of activity, users' practices of risk issues do not necessarily overlap with academic practices. Involving practitioners while controlling the quality of their contribution might be costly and time-consuming but it is in theory possible. It should be possible to introduce a reasonable proportion of grey literature coming from qualified sources, maybe selected from a list established by governments or NGOs as in the expert selection process. Another option could be to design a consultative process with interviews, workshops or study days. For instance, the French Association for Disaster Risk Reduction (AFPCN) designed an iterative process in which the Scientific Committee writes an introduction to a question, organise a study day inviting specialists and end-users, then writes a synthesis of the discussion and release it publically. The process is iterative and allows progressing toward a shared representation while explicating possible divergences. Risks, adaptation and mitigation solutions can then have a chance to be thought together in a theoretical as well as in a practical manner.

The recent change in scenario strategy might also be the opportunity to carry out a reorganisation of the process. Studies on impacts require a constant exchange of information with climate simulations, and the assessments would certainly benefit from a rapprochement between WGI and WGII on this topic. On the contrary, the topics of risk management, adaptation and mitigation policies can be treated relatively independently and could benefit from being opened up to a wider variety of actors. The integration of adaptation and mitigation pathways is another key challenge, and working at a well-thought-out scale on well-designed questions, with the relevant groups of stakeholders, could allow us to approach this question in a more pragmatic manner. Another way to approach the question could be to explore ways for the Panel to cooperate/discuss with others expert bodies working at the regional, national or local scales in order to articulate their knowledge of regional, national or local policies and practices.

\section{Conclusion}

The global dimension of the climate system hinders the implementation of concrete solutions. The Paris agreement nevertheless endorsed the emergence of a bottom-up dynamics that could help progressing toward the implementation of more efficient adaptation and mitigation strategies. The panel of actors who can act concretely on climate issues cannot be approached "globally", since they work in different countries, in different sectors and at different scales. Their actions respond to different rationales and there is little chance that they wish to address the "climate problem" in the same way. The success of the strategy adopted by the UNFCCC depends on 
the ability of actors to work beyond political, cultural, sectoral and institutional boundaries and, to that extent, expert bodies have to play a major role. The IPCC provides today the most highly developed expert-narratives on climate change and useful "living maps" that can be used to derive global policies. The current assessment process allows prioritizing different types of risks and, in that sense, greatly help initiate mobilisation on climatic issues at other scales. But it seems that the implementation of the Paris agreement, however, will require going beyond the current limits of the Panel.

In order to address the question of the evolution of the IPCC, the scientific council of the French Association for Disaster Risk Reduction developed an iterative and integrative process, interviewing climate experts, consulting experts from various sectors, and the wider public. This methodology led to identify limitations in the current expertise process such as the difficulty of many actors to apply the results of the expertise at their temporal and spatial scale, a lack of reflexivity of the Panel on the realities of the interactions between science and policy, a lack of integration of the expertise between academic disciplines, sectors and countries and a need for going further than the consensus-approach in the treatment of uncertainties. Recommendations can be summarised as follows: it would be important to communicate on why scientific and political considerations must be jointly taken into account to arrive at useful assessments and on the difficulties that are inherent to the translation from academic to operable knowledge (including uncertainties); it would be important to involve other categories of actors in the expertise process and working on focussed reports could provide the flexibility to go beyond disciplinary and sectorial boundaries; the current organisation of the working groups also has to be rethought in order to allow for iterative consultation and dialogue with all the parties of the climate response community as their views and experiences on working at the science-policy interface are valuable ones.

\section{Acknowledgment}

The authors want to thank their anonymous reviewers for very helpful comments in dealing with the first version of the manuscript. They are also grateful to AFPCN (http://afpcn.org/), the French Association for Disaster Risk Reduction, which facilitated interviews and seminars held during the preparation of this article. We are also thankful to those who agreed to be interviewed: $1 /$ for their role in IPCC reports: Hervé Le Treut (IPSL), Anny Cazenave, Katia Laval and Guy Laval (French Academy of Sciences); 2/ Michel Petit (French Academy of Agriculture) and Nicolas Bériot (Secretary General of the National Observatory on the Effects of Global Warming - ONERC), designated as former and current IPCC Focal Points in France, respectively. During the drafting of this article, Maud Devès benefited from funding under a research programme called "Earth politics" set up by the COMUE Sorbonne Paris Cité.

\section{References}

Agrawala, S. (1998a). Context and early origins of the Intergovernmental Panel on Climate Change. Climatic Change, 39(4), 605-620.

Agrawala, S. (1998b). Structural and process history of the Intergovernmental Panel on Climate Change. Climatic Change, 39(4), 621-642. 
Author-produced version of the article published in Environmental Science \& Policy (2017), vol. 78, p. 142-148

The original publication is available at http://www.sciencedirect.com/science/article/pii/S1462901117310109

Aubertin, C., Damian, M., Magny, M., Millier, C., Theys, J., Treyer, S. (2015) Introduction. Les enjeux de la conference de Paris. Penser autrement la question climatique. Natures Sciences Sociétés, 23, supplément, S3-S5, doi : 10.1051/nss/2015013

Aykut, S. C., Dahan, A. (2015). Gouverner le climat? 20 ans de négociations internationales.

Beck, S. (2011). Moving beyond the linear model of expertise? IPCC and the test of adaptation. Regional Environmental Change, 11(2), 297-306.

Beck, S. (2013). 71. Is the IPCC a learning organisation? New approaches to governance and decisionmaking, 418.

Beck, S., Borie, M., Chilvers, J., Esguerra, A., Heubach, K., Hulme, M., Nadim, T. (2014). Towards a reflexive turn in the governance of global environmental expertise. The cases of the IPCC and the IPBES. GAIA-Ecological Perspectives for Science and Society, 23(2), 80-87.

Bjurström, A., Polk, M. (2011). Climate change and interdisciplinarity: a co-citation analysis of IPCC Third Assessment Report. Scientometrics, 87(3), 525-550.

Bodansky, D. (2001). The history of the global climate change regime. International relations and global climate change, 23-40.

Bolin, B. (2007). A history of the science and politics of climate change. The Role of the Intergovernmental Panel on Climate Change, 36.

Brysse, K., Oreskes, N., O'Reilly, J., \& Oppenheimer, M. (2013). Climate change prediction: Erring on the side of least drama? Global Environmental Change, 23(1), 327-337.

Burton, I., Development Programme United Nations (2005). Adaptation policy frameworks for climate change: developing strategies, policies and measures (p. 258). B. Lim (Ed.). Cambridge: Cambridge University Press.

Church, J. A., Clark, P. U., Cazenave, A., Gregory, J. M., Jevrejeva, S., Levermann, A., ... \& Payne, A. J. (2013). Sea-level rise by 2100. Science,342(6165), 1445-1445.

Cody, E. M., Reagan, A. J., Mitchell, L., Dodds, P. S., Danforth, C. M. (2015). Climate change sentiment on Twitter: An unsolicited public opinion poll. arXiv preprint arXiv:1505.03804.

Cook, J., Nuccitelli, D., Green, S. A., Richardson, M., Winkler, B., Painting, R., Skuce, A. (2013). Quantifying the consensus on anthropogenic global warming in the scientific literature. Environmental Research Letters, 8(2), 024024.

Cooke, R. M. (2015). Messaging climate change uncertainty. Nature Climate Change, 5(1), 8-10.

Curry, J. (2011). Reasoning about climate uncertainty. Climatic Change, 108(4), 723-732.

Dahan, A. (2013). Historic overview of climate framing. FMSHWP-2013-39.

Dahan, A., Guillemot, H. (2015). Les relations entre science et politique dans le régime climatique: à la recherche d'un nouveau modèle d'expertise?. Natures Sciences Sociétés, (Supp. 3), 6-18.

Demeritt, D. (2001). The construction of global warming and the politics of science. Annals of the association of American geographers, 91(2), 307-337.

Devès, M.H., Bourrelier, P.H., Décamps, H., Lang, M., Le Bars, Y. (2014). Examen de la méthodologie d'expertise du GIEC (IPCC) sur le changement climatique. Conseil Scientifique de l'Association 
Author-produced version of the article published in Environmental Science \& Policy (2017), vol. 78, p. 142-148

The original publication is available at http://www.sciencedirect.com/science/article/pii/S1462901117310109

Française de Prévention des Catastrophes Naturelles (AFPCN). http://afpcn.org/wordpress/wpcontent/uploads/2014/01/AFPCN_ExamenGIEC_v12dec2014.pdf

Devès, M.H. (2014). Les risques associés au changement climatique : point sur la synthèse de l'AR5 et gestion des risques littoraux, Synthèse du débat du 7 mai 2015. AFPCN, 9 juin 2015, http://afpcn.org.

Dovers, S. R., Hezri, A. A. (2010). Institutions and policy processes: the means to the ends of adaptation. Wiley Interdisciplinary Reviews: Climate Change, 1(2), 212-231.

Ebi, K. L. (2011). Differentiating theory from evidence in determining confidence in an assessment finding. Climatic change, 108(4), 693-700.

Edenhofer, O., Minx, J. (2014). Mapmakers and navigators, facts and values. Science, 345(6192), 3738.

Ekwurzel, B., Frumhoff, P. C., McCarthy, J. J. (2011). Climate uncertainties and their discontents: increasing the impact of assessments on public understanding of climate risks and choices. Climatic change, 108(4), 791-802.

Franz, W. E. (1997). The development of an international agenda for climate change: connecting science to policy. Belfer Center for Science and International Affairs discussion paper E-97-07. Cambridge, MA: Kennedy School of Government, Harvard University. Also International Institute for Applied Systems Analysis interim report IR-97-034/August. Environment and Natural Resources Program.

Gray et al. (2013) http://www.medialab.sciences-po.fr/ipcc/

Hajer, M. A. (2012). A media storm in the world risk society: enacting scientific authority in the IPCC controversy (2009-10). Critical policy studies, 6(4), 452-464.

Hecht, A.D. and Tirpak, D. (1995). Framework agreement on climate change: A scientific and policy history. Climatic Change, 29, 4, pp. 371.

Hollin, G. J. S., Pearce, W. (2015). Tension between scientific certainty and meaning complicates communication of IPCC reports. Nature Climate Change.

Howe, P. D., Mildenberger, M., Marlon, J. R., Leiserowitz, A. (2015). Geographic variation in opinions on climate change at state and local scales in the USA. Nature Climate Change, 5(6), 596-603.

Hulme, M., Mahoney, M. (2010). Climate change: What do we know about the IPCC?. Progress in Physical Geography.

Hulme, M., Zorita, E., Stocker, T. F., Price, J., Christy, J. R. (2010). IPCC: cherish it, tweak it or scrap it. Nature, 463(11), 730-732.

InterAcademy Council (2010). Climate Change Assessments: Review of the Processes and Procedures of the IPCC.

IPCC (1990). Report prepared for Intergovernmental Panel on Climate Change by Working Group I J.T. Houghton, G.J. Jenkins and J.J. Ephraums (eds.). Cambridge University Press, Cambridge, Great Britain, New York, NY, USA and Melbourne, Australia, 410 pp.

IPCC (2010). Guidance Note for Lead Authors of the IPCC Fifth Assessment Report on Consistent Treatment of Uncertainties, 6-7 July, 7p. 
Author-produced version of the article published in Environmental Science \& Policy (2017), vol. 78, p. 142-148

The original publication is available at http://www.sciencedirect.com/science/article/pii/S1462901117310109

IPCC (2015), IPCC takes decisions on future work, IPCC press release, 27 February 2015, 2015/7PR, URL: https://www.ipcc.ch/news_and_events/docs/p41/P41_closing_press_release.pdf

Jasanoff, S., Lynch, M., Miller, C., Wynne, B., Buttel, F., Charvolin, F., Lambright, W. H. (1998). Science and decision making.

Jones, N. (2011). The latest iteration of IPCC uncertainty guidance-an author perspective. Climatic Change, $108(4), 733-743$

Jones, N. (2013). Climate assessments: 25 years of the IPCC. Nature, 501, 298-299.

Kintisch, E. (2010). IPCC Seeks' Broader Community Engagement to Correct Errors. Science, 327(5967), 768-769.

Maslin, M. (2013). Cascading uncertainty in climate change models and its implications for policy. The Geographical Journal, 179(3), 264-271.

Miller, C. (2001). Hybrid management: boundary organizations, science policy, and environmental governance in the climate regime. Science, Technology \& Human Values, 26(4), 478-500.

Moss, R. H., Edmonds, J. A., Hibbard, K. A., Manning, M. R., Rose, S. K., Van Vuuren, D. P., Meehl, G. A. (2010). The next generation of scenarios for climate change research and assessment. Nature, 463(7282), 747-756.

O'Reilly, J., Oreskes, N., Oppenheimer, M. (2012). The rapid disintegration of projections: the west Antarctic ice sheet and the Intergovernmental Panel on Climate Change. Social Studies of Science, 42(5), 709-731.

Oppenheimer, M., O'Neill, B. C., Webster, M., Agrawala, S. (2008). The limits of consensus. Science, 123.

Oreskes, N. (2004). The scientific consensus on climate change. Science,306(5702), 1686-1686.

Pielke, R. A. (2005). Misdefining "climate change": consequences for science and action. Environmental Science \& Policy, 8(6), 548-561.

Pielke, R. (2010). The climate fix: what scientists and politicians won't tell you about global warming. Basic books.

Sarewitz, D. (2011). Does climate change knowledge really matter? Climate Change, 2(4), 475-481.

Schiermeier, Q. (2010a). IPCC signs up for reform. Nature, 467(7318), 891-892.

Schiermeier, Q. (2010b). IPCC flooded by criticism. Nature, 463(7281), 596-597.

Schiermeier, Q. (2014). IPCC report under fire. Nature, 508(7496), 298-298.

Schrope, M. (2001). Consensus science, or consensus politics? Nature, 412(6843), 112-114.

Skodvin, T. (2000). The Development of an International Regime on a Human-Induced Climate Change. In Structure and Agent in the Scientific Diplomacy of Climate Change (pp. 93-103). Springer Netherlands.

Socolow, R.H. (2011). High-consequence outcomes and internal disagreements: tell us more, please. Climatic Change, 108 (4), 775-790.

Stern, N. (2006). Stern Review: the Economics of Climate Change, UK Government, 662p. 
Stocker, T. F., Plattner, G. K. (2014). Climate policy: Rethink IPCC reports. Nature, 513, 163-165.

Tol, R. S. (2011). Regulating knowledge monopolies: the case of the IPCC. Climatic change, 108(4), 827-839.

Tollefson, J. (2013). Study aims to put IPCC under a lens. Nature, 502, 281.

Vasileiadou, E., Heimeriks, G., \& Petersen, A. C. (2011). Exploring the impact of the IPCC Assessment Reports on science. Environmental Science \& Policy,14(8), 1052-1061.

Victor, D. G. (2015). Embed the social sciences in climate policy.

Zillman, J. W. (2009). Historique des activités climatologiques. Bulletin de l'OMM, 58(3), 141. 